\title{
Assessment of three dredging plans for a wave-dominated inlet
}

Diogo Silva Mendes MSC

PhD student, CERIS, Instituto Superior Técnico, Universidade de Lisboa, Lisbon, Portugal (corresponding author: ddiogosm@gmail.com)

André B. Fortunato $\mathrm{PhD}$

Senior Research Officer, Estuaries and Coastal Zones Division,

National Laboratory for Civil Engineering, Lisbon, Portugal

\author{
António A. Pires-Silva PhD \\ Assistant Professor, CERIS, Instituto Superior Técnico, Universidade \\ de Lisboa, Lisbon, Portugal
}

Many small wave-dominated inlets are naturally unstable and require regular dredging. To mitigate the costs of these operations, the dredged channels should be designed to bring the inlet close to equilibrium and minimise flood dominance. However, it is often unclear how to optimise the configuration of the channels. This study focuses on a small lagoon on the western Portuguese coast that has been subject to frequent and diverse interventions. A process-based morphodynamic model is applied to compare the dredging plan that has been followed for the last 15 years with two new alternatives. These alternative dredging plans increase the tidal prism and reduce flood dominance, mainly due to the higher channel cross-section. Secondary transverse channels do not affect the morphodynamics significantly. For future dredging operations, it is suggested that the bottom depth of the main natural channel be dredged to chart datum and a secondary channel be added to the previous channel with the same bottom depth and half of the channel width.

\section{Notation}

$d_{50} \quad$ sediment median grain diameter

$H_{\mathrm{s}} \quad$ significant wave height

$h \quad$ still-water depth (m)

$Q_{i} \quad$ sand flux along the axis $i\left(\left(\mathrm{~m}^{3} / \mathrm{s}\right) / \mathrm{m}\right)$

$T_{p} \quad$ wave peak period

$\Delta \mathrm{h} \quad$ bed update $(\mathrm{m})$

$\varepsilon \quad$ dimensionless diffusion coefficient

$\lambda \quad$ porosity (dimensionless)

\section{Introduction}

Shallow coastal lagoons with wave-dominated inlets are commonly found in micro-tidal or meso-tidal coasts with a very energetic wave regime (Hayes, 1979; Hayes and FitzGerald, 2013). Worldwide, their economic and environmental importance has been growing since several activities are concentrated in these coastal areas, such as construction development on the barrier islands, aquaculture, fishing and recreational activities. However, these coastal lagoons frequently close due to sediments transported landwards during storms or the littoral drift when the ebb currents are weak (Bertin et al., 2009; Ranasinghe and Pattiaratchi, 2003) or when the fluvial discharge is of minor importance (Elwany et al., 1998; Shuttleworth et al., 2005). Inlet closure prevents navigation, deteriorates water quality and promotes marginal inundations.
Common solutions are artificial opening (Pacheco et al., 2011), maintenance dredging and, in some cases, a single- or doublejetty system (Keshtpoor et al., 2015; Zippel and Thomson, 2015). However, dredging operations are expensive, and jetties have high visual and environmental impacts. The long-term impact of dredging operations should therefore be optimised.

This study focuses on the Óbidos lagoon, located on the western Portuguese coast (Figure 1). This coastal lagoon is connected to the sea through a wave-dominated inlet where the combination of waves and tidal currents frequently induces closure or shoaling of the inlet mouth. Such closures prevent water renewal, which degrades water quality and causes marginal inundations, while migration of the inlet mouth to the northern and southern margins puts neighbouring constructions at risk. Several emergency solutions have been employed in past decades to bring the inlet close to equilibrium (Oliveira et al., 2006). Overall, and despite all the efforts, keeping the inlet open requires frequent large-scale dredging operations, as illustrated by the recent closures in January 2014 and March and April 2015.

Bruneau et al. (2011) suggest that the Óbidos lagoon inlet has two stable equilibrium states. However, the authors believe that these equilibrium states should be regarded as preferential states, which are more persistent than others, rather than 


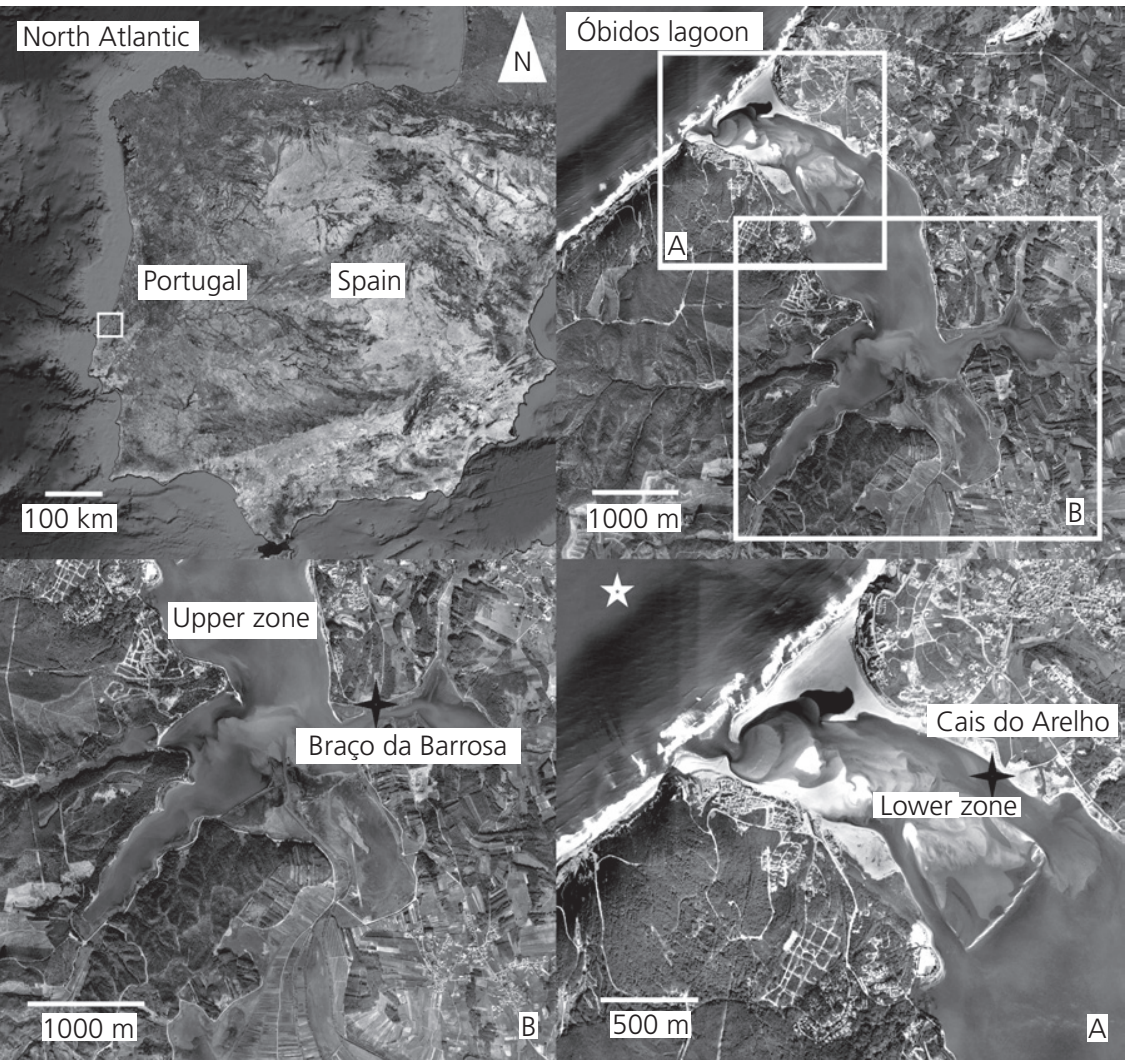

Figure 1. The Óbidos lagoon: location, place names and monitoring stations (adapted from the free version of

GoogleEarthPro)

perennial. A similar concept was put forward by Hinwood and McLean (2015) and Hinwood et al. (2012), who proposed using the concept of attractors to describe a transient - yet persistent - state of a tidal inlet. One of the equilibrium states proposed by Bruneau et al. (2011) has a shorter inlet channel. It therefore has the potential for lower tidal dissipation, larger tidal prisms and higher stability.

The most common human interventions adopted in past decades were dredging operations to reposition the inlet in a central location and to shorten and deepen the inlet channel. Combined with dredging operations, several rows of sandbags were also placed along the margins to restrict the movement of the inlet mouth, thereby protecting constructions located on the margins. Moreover, a $200 \mathrm{~m}$ long sheet-pile curtain was built near the northern margin to stabilise the position of the inlet channel (Vieira, 2001). More traditional engineering solutions comprising two jetties were proposed, but were never implemented, mainly due to interruption of the littoral drift and the high visual impact (Fortunato and Oliveira, 2007a). A major dredging plan $\left(15 \times 10^{6} \mathrm{~m}^{3}\right)$ was subsequently proposed in order to increase the lagoon surface area and, consequently, the tidal prism. However, this solution proved unfeasible due to its cost and doubts raised about its efficacy (Fortunato and Oliveira, 2007a).

The dredging operations implemented in the last 15 years were made in accordance with a dredging plan proposed by the Danish Hydraulic Institute (DHI) (Vieira, 2001), which aimed at creating a stable inlet channel (Figure 2(a)). The dredging plan constitutes one main dredged channel with a variable width. At the upstream part of the flood delta, this channel is close to the northern margin and is $70 \mathrm{~m}$ wide. It is dredged $1.0 \mathrm{~m}$ above the chart datum $(\mathrm{CD}$, corresponding approximately to the lower spring low tide of the coast). Near the inlet mouth, the channel is located in a central position. Here, it has a width of $80 \mathrm{~m}$ and is dredged $0.5 \mathrm{~m}$ above the CD. Connection with the upstream trench is made with a meander around the sheet-pile curtain. At the meander, the bottom depth is dredged $1.0 \mathrm{~m}$ above the $\mathrm{CD}$ and the channel is $100 \mathrm{~m}$ wide. This channel was dredged in 1999, 2001, 2003 and 2013. In spite of these large-scale operations, several 


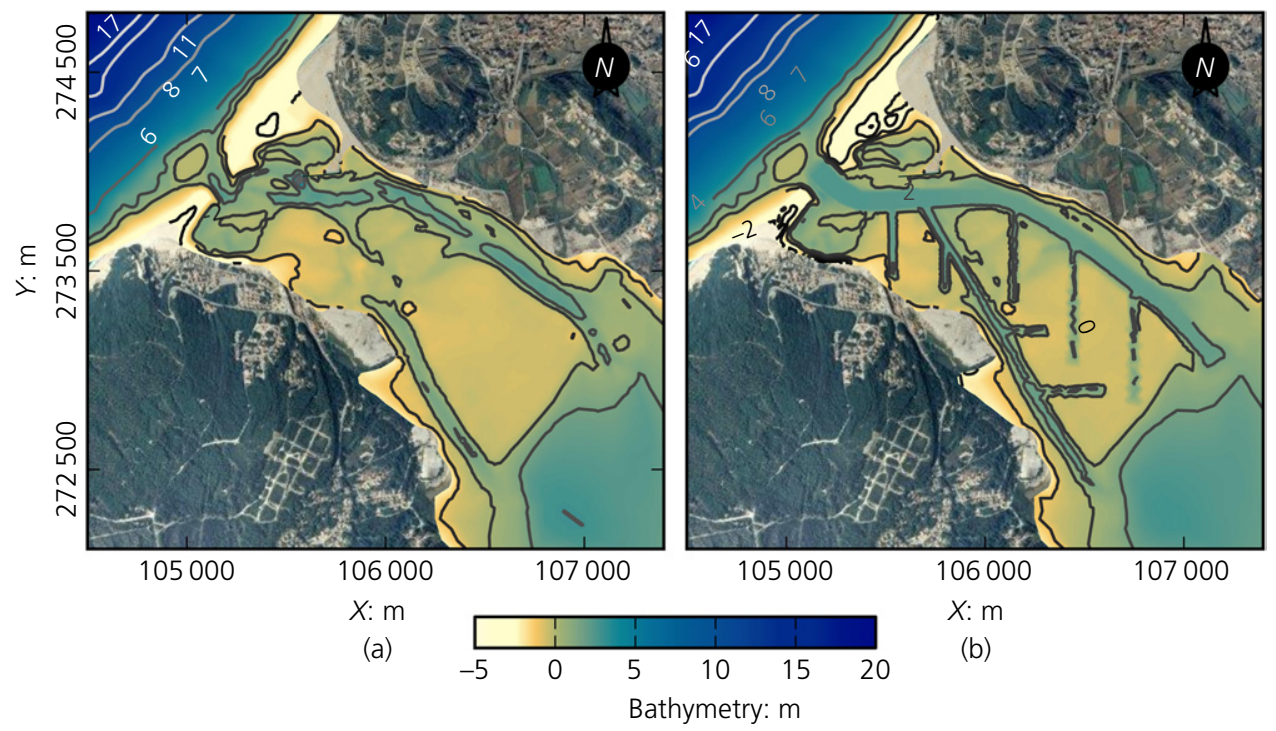

Figure 2. Bathymetries relative to mean sea level, $2 \mathrm{~m}$ above CD.

(a) Dredging solution proposed by the $\mathrm{DHI}$ and (b) dredging

solution proposed by Fortunato and Oliveira (2007a) without the

guiding wall

smaller interventions were also required in these years to prevent or correct the closure of the inlet and the destruction of marginal constructions. The closure of the inlet in 2014, only months after dredging of the channel, shows that this operation constitutes a temporary solution.

Fortunato and Oliveira (2007a) proposed an innovative solution to stabilise the Óbidos lagoon inlet, comprising a partially submerged guiding wall and a new dredging plan. Figure 2(b) shows the same solution as presented by Fortunato and Oliveira (2007a) but without the guiding wall. This dredging plan constitutes two main dredged channels and seven transverse channels dredged over tidal flats that are $2.0 \mathrm{~m}$ above CD. These transverse channels aim at reducing the ebb duration (Fortunato and Oliveira, 2004) and removing sediments from the ever-growing flood delta. The width of the northern main channel varies between $70 \mathrm{~m}$ upstream and $100 \mathrm{~m}$ at the inlet, and the southern channel has a constant width of $30 \mathrm{~m}$. The seven transverse channels are $25 \mathrm{~m}$ wide. Their total combined length is $3 \mathrm{~km}$, and they should be dredged with an angle of $\sim 45^{\circ}$ to the main channels to maximise the seaward residual sediment fluxes (Fortunato and Oliveira, 2004). The lateral slopes of all channels are 1:10. The channel near the inlet should be dredged $0.5 \mathrm{~m}$ below the $\mathrm{CD}$ and the remaining channels to the $\mathrm{CD}$ due to dredge vessel specifications.

The purpose of this study was twofold. First, three dredging plans designed to optimise the configuration of a wave-dominated inlet were compared. The second objective was to investigate the impact of adding transverse channels. The three dredging plans are the dredging plan proposed by the DHI (hereafter called DP1), the scheme proposed by Fortunato and Oliveira (2007a) without the guiding wall (hereafter DP2) and a variant of the latter, comprising a single transverse channel (hereafter DP3).

Section 2 of this paper characterises and describes the Óbidos lagoon. Section 3 presents the morphodynamic model used. Section 4 covers verification of the morphological evolutions simulated by the morphodynamic model and an assessment of the two proposed dredging plans, comparing both with the dredging plan used in the last decade. Section 5 summarises the main conclusions.

\section{Description of the study site}

\subsection{Geomorphological characterisation}

The Óbidos lagoon is a shallow coastal system located on the western Portuguese coast with a narrow $(<100 \mathrm{~m})$ wavedominated inlet that comprises the connection between the lagoon and the open sea. The average depth is $2.5 \mathrm{~m}$ below CD. It has a maximum width of $1.8 \mathrm{~km}$, and the total distance between the inlet and the main tributaries is $4.5 \mathrm{~km}$ (Freitas et al., 1992). Morphologically, the Óbidos lagoon can be divided into an upper and a lower zone (Figure 1). The upper zone consists of cohesive sediments, while in the lower zone, 


\section{Offprint provided courtesy of www.icevirtuallibrary.com Author copy for personal use, not for distribution}

the vast majority of sediments are sands with a sediment median grain diameter $\left(d_{50}\right)$ ranging from 0.4 to $0.8 \mathrm{~mm}$ (Bruneau et al., 2011). In the lower zone, the combined effects of waves and tidal currents lead to a complex system of meanders and sand banks (Figure 1). At the inlet, these effects induce morphological evolutions that can occur on monthly time scales (Oliveira et al., 2006). During the maritime summer, the sediments are mainly transported by tidal currents, and the Óbidos lagoon is naturally capable of maintaining its inlet opened, even displaying a natural tendency for enlargement. However, the very energetic wave regime characterised by large swell waves during the maritime winter leads to the transport of a substantial amount of sediments landwards, which often induces the inlet's closure (Bruneau et al., 2011).

\subsection{Hydrodynamic forcing}

The tidal regime is semi-diurnal with tidal ranges between 2 and $4 \mathrm{~m}$ at the coast and 1-2 $\mathrm{m}$ inside the lagoon (Oliveira et al., 2006). The wave climate is mild to severe and can be briefly summarised by a significant wave height $\left(H_{\mathrm{s}}\right)$ larger than $1 \mathrm{~m} 88 \%$ of the time, and occasionally reaching $6 \mathrm{~m}$ in the maritime winter (Bruneau et al., 2011). The mean wave direction (MWD) is confined to a sector between 255 and $345^{\circ} \mathrm{N}$ but the most frequent $\mathrm{MWD}$ is $315^{\circ} \mathrm{N}$ (perpendicular to the coastline). The wave peak period $\left(T_{\mathrm{p}}\right)$ varies between 5 and $20 \mathrm{~s}$ (Bertin et al., 2009). The fluvial discharge is concentrated in three main tributaries - Vala do Ameal, Arnóia and Cal. The freshwater input is negligible because it only represents $5 \%$ of the tidal prism scaled by the $M_{2}$ period (Oliveira et al., 2006). Therefore, the Óbidos lagoon may be considered a well-mixed lagoon.

\subsection{Environmental data}

In 2001, a comprehensive monitoring campaign was carried out. Between July and November 2001, the wave parameters in front of the inlet and the water levels inside the lagoon were recorded along with two bathymetric surveys inside the lagoon. The wave characteristics were intermittently recorded by the Portuguese Hydrographic Institute (IH, 2001) from July to September 2001 in front of the Óbidos lagoon inlet. These data were obtained using an acoustic Doppler current profiler deployed at $23 \mathrm{~m}$ depth (CD). Water levels were measured by two tidal gauges, one located near the inlet (at Cais do Arelho) and the other at the upstream boundary of the lagoon (at Braço da Barrosa). These tidal gauges had a sample period of $6 \mathrm{~min}$ and measured the sea surface elevations between July and November 2001. The bathymetric surveys were performed by boat inside the lagoon in July 2001 and in November 2001.

\section{Methodology}

\subsection{Description of the morphodynamic model} The morphodynamic model used simulates the non-cohesive sediment dynamics and the morphological changes in estuaries and coastal inlets under the combined effect of waves and tidal currents. The model comprises the wave propagation model WWM-II (Roland et al., 2012), the circulation model Selfe (Zhang and Baptista, 2008) and the sediment transport and bottom evolution model Sed2D (Dodet, 2013). In order to provide flexibility and efficiency, these models share the same unstructured grid, which allows adaptation to complex coastal environments, and are fully parallelised.

WWM-II solves the wave action equation that describes the evolution of the wave spectrum over time and geographical and spectral spaces. The relevant physical processes in shallow waters are included in the model, such as wave shoaling, bottom-induced refraction and breaking, bottom friction, triad wave-wave interactions and current-induced wave blocking and refraction. The outputs of WWM-II are used to compute the gradients of radiation stresses necessary to force Selfe and to evaluate the sediment fluxes in Sed2D.

The version of Selfe used in this work solves the $2 \mathrm{DH}$ shallowwater equations with the Boussinesq approximation. The bottom friction is determined using a Manning friction law with a spatially variable coefficient. The water levels and tidal currents obtained by Selfe are fed back into WWM-II to calculate the current-induced wave shoaling and refraction and into Sed2D to calculate the sediment fluxes.

Following Fortunato and Oliveira (2004), Sed2D solves the Exner equation (Equation 1) with a node-centred finite-volume technique to update the bottom bathymetry

$$
\text { 1. } \Delta h=\frac{1}{1-\lambda} \nabla\left[Q+\varepsilon(1-\lambda)\left(\left|Q_{x}\right| \frac{\partial h}{\partial x}+\left|Q_{y}\right| \frac{\partial h}{\partial y}\right)\right]
$$

where $h$ is the water depth, $\lambda$ is the porosity, $\varepsilon$ is a dimensionless diffusion coefficient and $Q$ is the sand flux computed with one of the available semi-empirical formulas. The sediment transport formula of Van Rijn (2007a, 2007b), which accounts for bed load, suspended load and wave-current interaction, was used to compute the sediment fluxes over the domain.

\subsection{Modelling set-up}

The unstructured grid, generated in the paper by Bruneau et al. (2011), has 29398 nodes and 57880 elements with a spatial resolution between $1600 \mathrm{~m}$ at the ocean boundary and $6 \mathrm{~m}$ at the inlet. The initial bathymetry of July 2001 (Figure 2 (a)) was measured by the Portuguese Hydrographic Institute (IH, 2001) soon after the dredging plan proposed by the DHI was implemented in May/June 2001.

The offshore boundary conditions are provided by regional models. The wave model WaveWatchIII (hereafter WW3) 


\section{Offprint provided courtesy of www.icevirtuallibrary.com Author copy for personal use, not for distribution}

(Tolman, 2009) is run in two nested grids, following Dodet et al. (2010), and provides the two-dimensional wave spectrum every $3 \mathrm{~h}$. Tidal elevations for the major 20 tidal constituents are computed with a regional application of Selfe (Fortunato et al., 2016). The atmospheric pressure is considered constant with a value of $1015 \mathrm{HPa}$ since the estimated standard deviation was $3 \mathrm{HPa}$ during the period between July and November 2001.

Deep-water effects, namely white capping and quadruplet wave-wave interactions, were not considered in the local wave model to reduce the computational effort. The wind forcing was neglected due to computational time constraints because the domain in the analysis is small, with a fetch of $11 \mathrm{~km}$ over an area of $210 \mathrm{~km}^{2}$. The reduction of the computational costs also led to restricting the frequency and direction bins to 12 . To model the horizontal turbulence, a spatial constant eddy viscosity coefficient of $1 \mathrm{~m}^{2} / \mathrm{s}$ was adopted.

Solving the Exner equation can cause spurious morphological oscillations. To circumvent these effects, the use of filters is common in such models. Sed2D has three built-in filters: an extrema filter, a slope filter and a diffusive filter. The extrema filter eliminates local extrema while preserving mass by averaging the depth at nodes with local extrema and neighbours (Fortunato and Oliveira, 2000). The slope filter mimics gravity effects on steep bottoms to prevent large gradients on the wet and dry zones (Roelvink et al., 2009). The diffusive filter aims to prevent the development of numerical oscillations by adding diffusion along the flow direction (Fortunato and Oliveira, 2007b). The median grain diameter was chosen in accordance with the sampling analysis described above, following Bruneau et al. (2011).

\section{Morphodynamic model simulations}

\subsection{Morphodynamic model verification}

To verify the wave model, a simulation of $95 \mathrm{~d}$, with a $3 \mathrm{~d}$ ramp period, was performed between 1 July and 30 September 2001. The wave model was run alone since the wave buoy is located deep enough (around $23 \mathrm{~m}$ depth) where waves do not interact with bottom bathymetry or the ambient currents. The verification of the coupled wave and hydrodynamic models was assessed with a simulation of $21 \mathrm{~d}$ with a ramp period of $1 \mathrm{~d}$ between 17 July and 6 August 2001. This temporal interval was chosen to validate the coupled model because it was considered small enough for the morphological evolutions to be neglected. Finally, to evaluate the predictions of the full morphodynamic model, a simulation of $156 \mathrm{~d}$ from July to November 2001, with $3 \mathrm{~d}$ of ramp period, was made and the results were compared with the bathymetric data collected in November 2001. The coefficients used in the morphodynamic model are presented in Table 1.

\begin{tabular}{ll} 
Coefficient & Setting \\
\hline WWM-II & \\
WWM-II time step & $300 \mathrm{~s}$ \\
Direction bins & 12 (southwest to northeast) \\
Frequency bins & $12(0 \cdot 2-0.05 \mathrm{~Hz})$ \\
Bottom friction coefficient & $0.067 \mathrm{~m}^{2} / \mathrm{s}^{3}$ \\
Wave breaking coefficient & 0.78 \\
Selfe & \\
Selfe time step & $20 \mathrm{~s}$ \\
Horizontal eddy viscosity & $1 \mathrm{~m}^{2} / \mathrm{s}$ \\
Water depth for wetting & $0.01 \mathrm{~m}$ \\
and drying & \\
Manning coefficient & Spatially variable (Bruneau \\
& et al., 2011) \\
Sed2D & \\
Sed2D time step & $20 \mathrm{~s}$ \\
Diffusion coefficient & 2 \\
Maximum slope for wet/dry & $11 / 45^{\circ}$ \\
elements &
\end{tabular}

Table 1. Coefficients used in the morphodynamic model

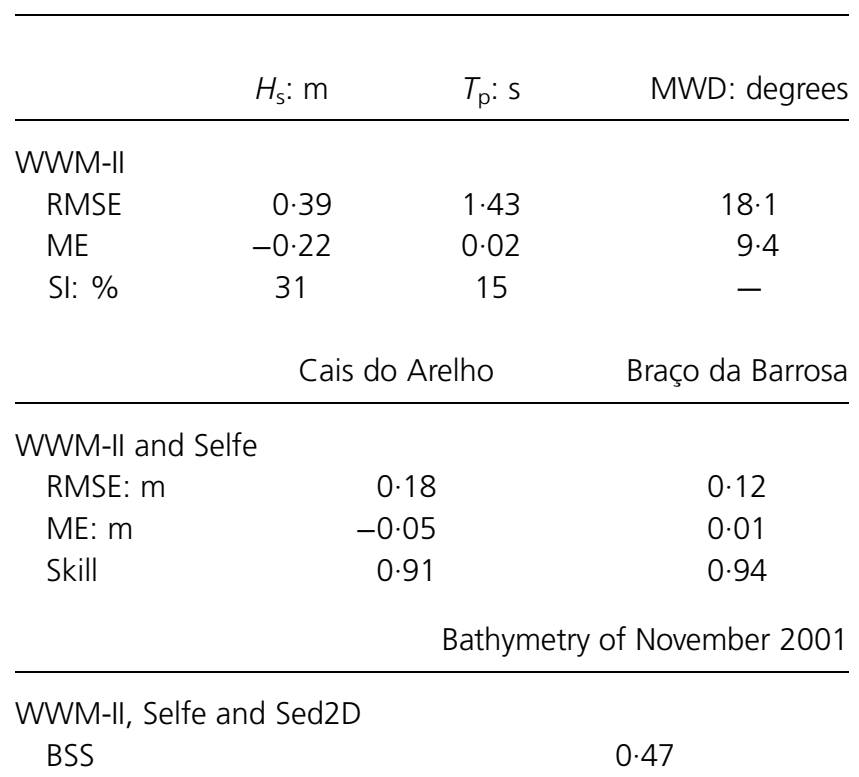

Table 2. Statistical error measures of the morphodynamic model

The statistical error measures used to verify the wave model were the root mean square error (RMSE), the mean error (ME) and the scatter index (SI), as in the paper by Teles et al. (2012). The results (Table 2) are in line with the results published by other authors (Dodet et al., 2013; Teles et al., 2012). They show fairly good behaviour and agreement between 
simulations and observations: the wave model underestimated $H_{\mathrm{s}}$ by $0.22 \mathrm{~m}$, the $T_{\mathrm{p}}$ was well reproduced with an SI of $15 \%$ and the MWD had an average error of $9 \cdot 4^{\circ}$.

The coupling between the wave and the hydrodynamic model was validated through a comparison of the simulated and measured water levels for two tidal gauges inside the lagoon. The statistical error measures evaluated were the RMSE, the ME and the skill, as in the paper by Dias et al. (2009). The good reproduction of the water levels inside the lagoon (Table 2) was made evident by the values of the above-mentioned statistical errors. Both comparisons described provided a sufficient level of confidence to continue with the additional morphodynamic module.

The morphodynamic simulation between July and November 2001 was assessed with the Brier-skill score (BSS) proposed by Sutherland et al. (2004). The simulated DP1 bathymetry was compared against the measured bathymetry in November 2001 (Bertin et al., 2009; Bruneau et al., 2011). According to Sutherland et al. (2004), a BSS error of $0 \cdot 3-0 \cdot 5$ corresponds to 'good agreement'. The values obtained for BSS (Table 2) thus indicate that the morphodynamic model predictions showed good agreement with the morphological evolutions in the Óbidos lagoon. The inlet migration to the southern margin in November 2001, seen in the bathymetric survey, was not reproduced by the model. This behaviour is attributed to the high $d_{50}$ at the northern margin required to stabilise the morphodynamic model and to the absence of the swash transport that reduces the longshore sediment transport. Also, the cut-off to 12 frequency bins to reduce the computational time, and the related loss of the energy associated with the frequencies above $0 \cdot 2 \mathrm{~Hz}$, could decrease the wave energy near the inlet mouth.

The ability of the morphodynamic model to reproduce the inlet enlargement and infilling was tested with the methodology proposed by Bertin et al. (2009). The amplitude of the tidal constituent $M_{2}$ was calculated at the Cais do Arelho tidal gauge using both model results and data. The growth of the tidal amplitude in the maritime summer and its reduction in the autumn were successfully reproduced by the model, although with a lag of $15 \mathrm{~d}$ (Figure 3). This lag can be associated with uncertainty of the exact date of the initial bathymetry, which is unknown. This comprehensive verification of the morphodynamic model displayed a good capability to predict the morphological evolution of the Óbidos lagoon. Therefore, it is an appropriate tool to assess the morphodynamic evolution of the three dredging plans.

\subsection{Morphological simulations of the three dredging plans}

The morphological evolution of the lagoon from 1 July until 27 November 2001 for the three dredging plans displayed

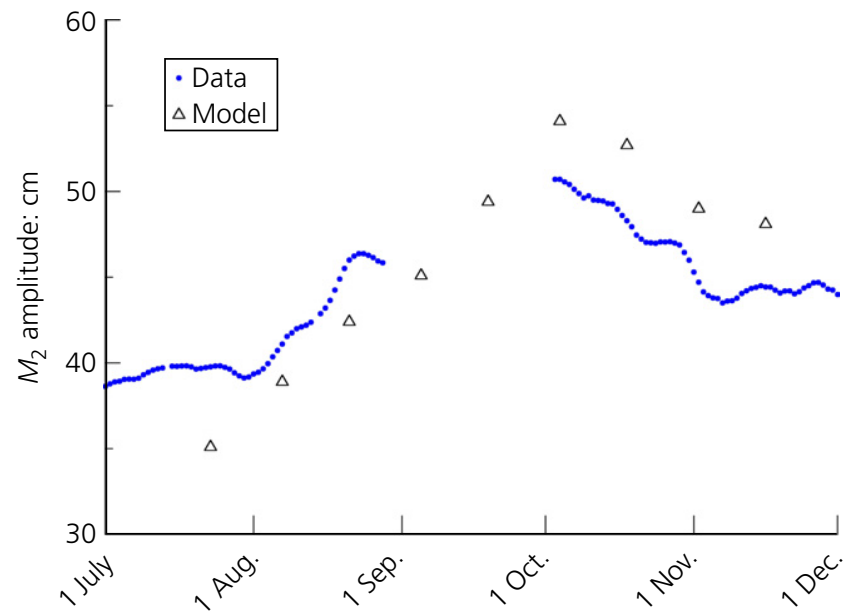

Figure 3. Evolution of the $M_{2}$ amplitude in Cais do Arelho from July to December 2001

some distinct behaviours (Figure 4). The northern main channel in DP1 displayed an unstable behaviour near the sheet-pile curtain because two meanders were formed (mark a). Moreover, strong sedimentation occurred in the sand bank south of the inlet transitional channel, which promoted the accretion of the downstream part of the flood delta (mark b).

The morphological evolutions of DP2 and DP3 were very similar to each other, but fairly different from DP1 (Figure 4). Both scenarios exhibited a stable northern main channel, without significant meanders. The transitional channel remained in a more central location. Dredging the main southern channel limits further accretion in the sand bank located between the two main channels (mark c). Also, the accretion at the beginning of the flood delta became restricted to a feature similar to a sand spit on the southern barrier island (mark d). After 5 months, DP2 and DP3 displayed a $40 \%$ wider and $25 \%$ deeper transitional channel when compared with DP1. These results reflect the characteristics of an ebb-dominated inlet with a more stable and wider transitional channel, where the ebb currents are the main agents that transport sediments seawards. Therefore, DP2 and DP3 presented a more stable morphological evolution than DP1.

The three transverse channels connected to the southern main channel increased the sediment transport along the south channel. At its downstream end, a sand bank similar to a flood delta developed, which will consequently constrict the main northern channel (mark e). They also increased the sediment transport near the connections with the southern main channel. This increase can allow a meander formation. The 

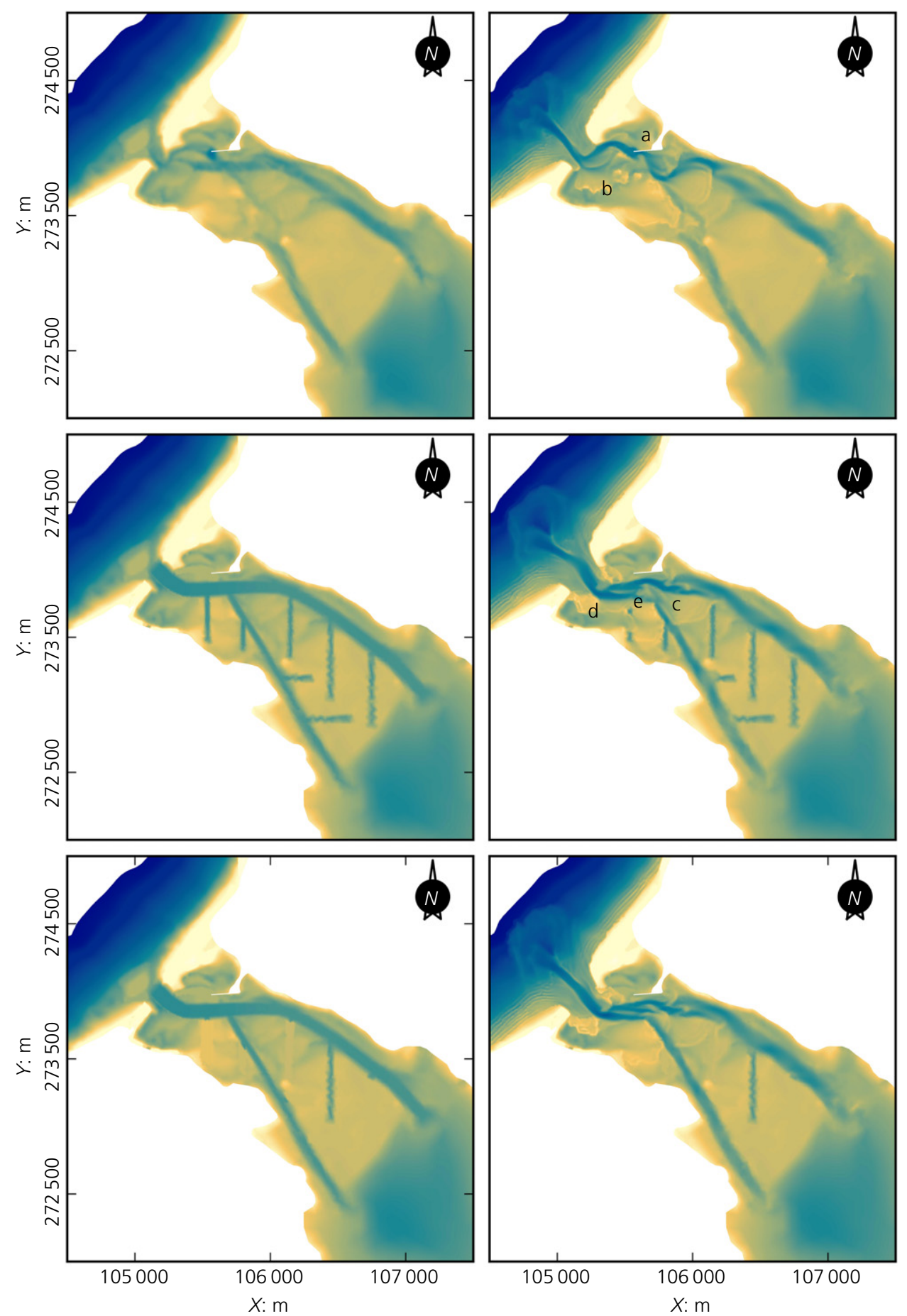

(a)

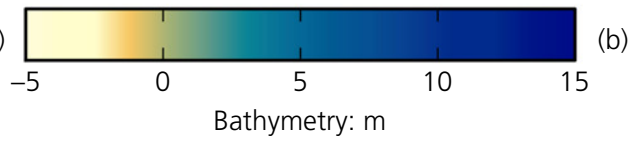

Figure 4. Bathymetries relative to mean sea level, $2 \mathrm{~m}$ above CD. (a) Initial bathymetry for DP1 (top), DP2 (middle) and DP3 (bottom). (b) Simulated bathymetry past 5 months for DP1 (top), DP2 (middle) and DP3 (bottom) 


\section{Offprint provided courtesy of www.icevirtuallibrary.com Author copy for personal use, not for distribution}

westernmost transverse channel in DP2 was fully accreted after 5 months, probably because it is approximately perpendicular to the northern main channel. Therefore, the qualitative comparison between DP2 and DP3 results suggest a less stable behaviour of the southern main channel when the transverse channels are present.

\subsection{Hydrodynamic characteristics of the three dredging plans}

The tidal prism is the volume of water that enters a lagoon during flood. In general, the stability of an inlet increases with the tidal prism (Bruun and Gerritsen, 1960). Time series of tidal prisms were computed for the three simulations. The results show that both DP2 and DP3 increase the tidal prism by roughly $50 \%$ relative to DP1 (Figure 5). However, this increase declines over time, suggesting that DP2 and DP3 lead to higher accretion rates than DP1. The benefits of these plans are therefore temporary. A rough estimate of the time scale of adjustment by a simple linear extrapolation of the trends in Figure 5 (thick lines) suggests that this period will be of the order of 1-2 years.

Sediments deposited inside coastal lagoons are transported seawards mainly by ebb currents. These currents are stronger if ebbs are shorter than floods. The differences between ebb and flood durations and the maximum ebb or flood velocities were calculated at two locations: inside the lagoon and near Cais do Arelho (Table 3). The ebb-flood differences between DP2 and DP3 are small, with an increase of $2 \%$ of the maximum ebb velocity at Cais do Arelho. These velocities are

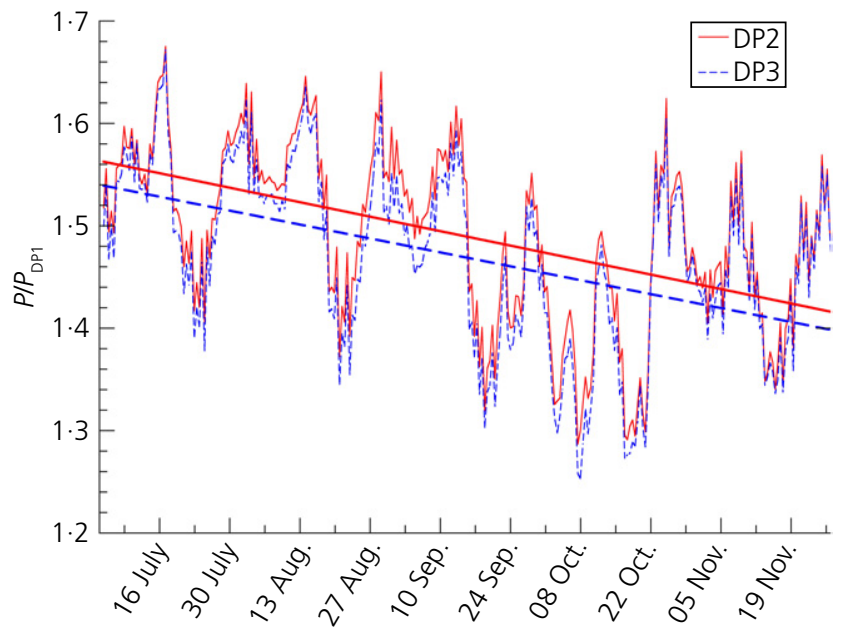

Figure 5. Time series of the ratio between the tidal prisms of DP2 (solid line) and DP3 (dashed line) with the tidal prism of DP1. The thick lines represent linear regression curves high enough to keep the main northern channel near Cais do Arelho stable for every dredging plan, thereby flushing out the sediments accumulated in that channel. Also, the differences in ebb and flood durations of DP2 and DP3 compared with DP1 were reduced on average by $25 \%$ at the central zone of the Óbidos lagoon and by $63 \%$ at Cais do Arelho. Therefore, the results show that DP2 and DP3 promote ebb dominance relative to DP1: the flood durations increase and the ebb velocities increase.

The ratio between tidal amplitudes inside and outside the lagoon (Figure 6(b)) shows a strong fortnightly behaviour for all the dredging plans. This behaviour is associated with the neap/spring tidal cycle (Figure 6(a)). On spring tides, velocities increase at the inlet, thereby increasing the dissipation of tidal energy. Conversely, the smaller velocities on neap tides reduce the damping of the tide inside the lagoon and the ratio decreases. There is no evidence of any phenomenon (storm) that affects DP2/DP3 differently from DP1 because the curves are equidistant. The small differences between the results for DP2 and DP3 suggest that the impact of the transverse channels is very small. There is also an average difference of 0.3 in the ratios between DP2/DP3 and DP1. This increase is subjacent to higher tidal prisms, which will lead to more stable dredging solutions.

\subsection{Bathymetric differences between the three dredging plans}

The differences between the initial and final bathymetries over 5 months highlight the areas of erosion and accretion inside the Óbidos lagoon for the three dredging plans (Figure 7). DP1 displays a large accretion zone at the seaward end of the flood delta, which leads to the formation of the downstream meander of the northern main channel. This meander increases the length of the inlet channel, enhances tidal dissipation and reduces the tidal prism.

\begin{tabular}{lrcc}
\hline & \multicolumn{3}{c}{ Difference: min } \\
\cline { 2 - 4 } & DP1 & DP2 & DP3 \\
\hline Cais do Arelho & 89 & 33 & 32 \\
Central zone of the & 165 & 126 & 123 \\
$\quad$ Óbidos lagoon & \multicolumn{3}{c}{ Maximum velocities: $\mathrm{m} / \mathrm{s}$} \\
Cais do Arelho & $1.22(1 \cdot 22)$ & $1 \cdot 27(1 \cdot 22)$ & $1 \cdot 24(1 \cdot 21)$
\end{tabular}

Table 3. Average differences between ebb and flood durations, and maximum ebb (flood) velocities at two locations in the Óbidos lagoon during the 5-month period 


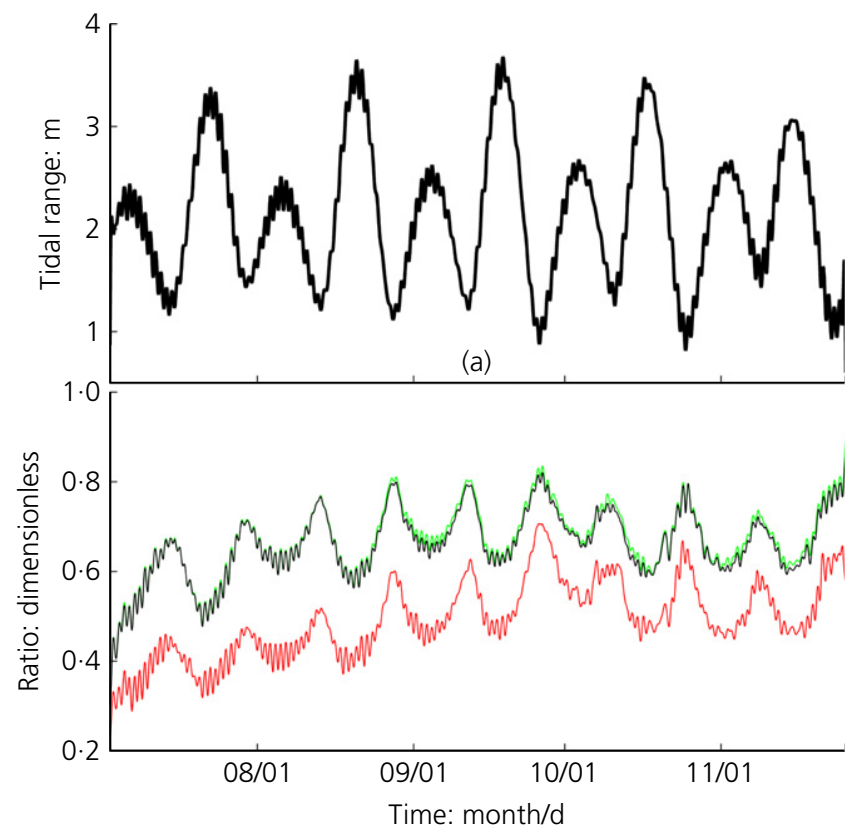

(b)

Figure 6. (a) Tidal amplitude outside the lagoon. (b) Ratio between tidal amplitude inside (at Cais do Arelho) and outside the lagoon for DP1 (lower plot), DP2 (uppermost of the top two plots) and DP3 (lower of the top two plots) from July to the end of November 2001

The addition of the southern channel in DP2 and DP3 seems to prevent the progression of the accretion landwards of the seaward end of the flood delta. Also, the main northern channel remained in a fixed position in the DP2 and DP3 simulations. In contrast, the same channel progressively developed meanders in the DP1 simulation, a clear evidence of instability. Differences between DP2 and DP3 can be observed at the southern main channel since the southern transverse channels improved the accretion in the previous channel. Therefore, the comparison suggests that the four transverse channels connected to the southern main channel promoted accretion, thereby reducing the discharge capacity of the southern main channel.

\section{Conclusions}

Three dredging plans designed to improve the stability of a wave-dominated inlet were assessed using a process-based morphodynamic model. The methodology presented in this study proved adequate to investigate dredging solutions and can be further used in other sites with wave-dominated inlets. Overall, this study allows the understanding of the morphological evolution of a coastal lagoon with a wavedominated inlet with three distinct dredging plans and presents a methodology to evaluate dredging plans in wave-dominated inlets.

The results show that dredging a second main channel in the southern part of the lagoon improves the stability of the inlet. In the short term, flood dominance decreases, ebb velocities grow and the tidal prism increases. Furthermore, this channel reduces the formation of a flood delta, which leads to the meandering of the inlet channel. As this meander contributes to lengthening the inlet channel and reducing the tidal prism, avoiding its generation is particularly beneficial to the stability of the inlet. However, these benefits of the second main channel are expected to be temporary and will gradually fade away over 1 or 2 years.

The benefits of dredging transverse secondary channels were unclear. While these channels slightly increased the tidal prism, they also promoted accretion at the main southern channel and constricted the main northern channel by creating a feature similar to a flood delta. Hence, they may have negative impacts in the long run.

For future dredging applications in similar coastal lagoons with wave-dominated inlets, it is advisable to increase the bottom depths to the $\mathrm{CD}$ (approximately the lower low tide in the ocean) and the width of the main natural channel in order to improve the inlet stability by increasing the tidal prism and the ebb dominance. The secondary channel (the southern main channel in this study) should be dredged to the CD and must have a width half that of the main channel and be at an angle of $\sim 45^{\circ}$ to the main channel to maximise the residual ebb fluxes.

Numerical simulations were performed from July to the end of November 2001. Further studies are therefore required to understand the complex evolution cycle of the inlet, from the dredging operation to the natural closure (Fortunato et al., 2014). In particular, these studies should include the winter season because the wave regime is more energetic, thereby increasing the morphological changes in wavedominated inlets and even leading to inlet closure. The higher tidal prisms obtained by dredging larger volumes of sand are expected to keep the inlet from closing in the winter months. However, this behaviour should be verified and quantified.

\section{Acknowledgements}

The authors thank the developers of Selfe, WWM-II and Sed2D for making their source codes available. The authors also thank Kai Li, Dr Xavier Bertin and Dr Guillaume Dodet for their help in implementing the model and Dr Alberto Azevedo and Dr Marta Rodrigues for their help in generating the figures. This work makes use of results produced with the support of the Portuguese National Grid Initiative; more information is available at https://wiki.ncg.ingrid.pt. 

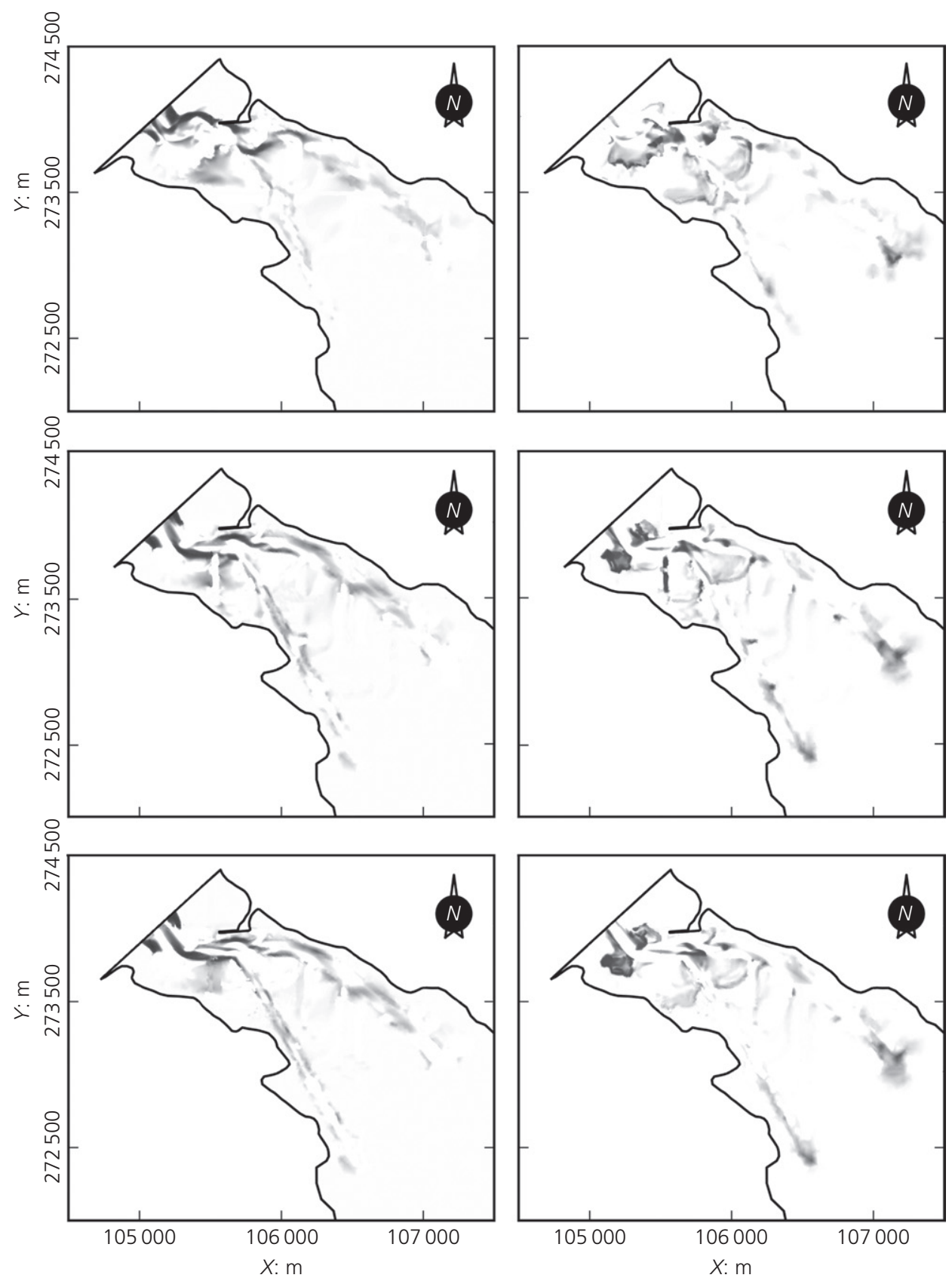

(a)
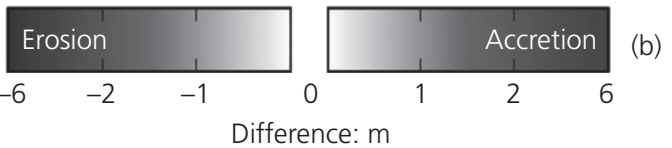

Figure 7. Erosion (a) and accretion (b) patterns between the

initial and the final bathymetries for DP1 (top), DP2 (middle) and

DP3 (bottom) 


\section{REFERENCES}

Bertin X, Fortunato AB and Oliveira A (2009) A modeling-based analysis of processes driving wave-dominated inlets. Continental Shelf Research 29(5): 819-834.

Bruneau N, Fortunato AB, Dodet G et al. (2011) Future evolution of a tidal inlet due to changes in wave climate, sea level and lagoon morphology (Óbidos Lagoon, Portugal). Continental Shelf Research 31(18): 1915-1930.

Bruun P and Gerritsen F (1960) Stability of coastal inlets. Coastal Engineering Proceedings 1(7): 386-417.

Dias JM, Sousa MC, Bertin X, Fortunato AB and Oliveira A (2009) Numerical modeling of the impact of the Ancão Inlet relocation (Ria Formosa, Portugal). Environmental Modelling and Software 24(6): 711-725.

Dodet G (2013) Morphodynamic Modelling of a Wave-dominated Tidal Inlet: The Albufeira Lagoon. $\mathrm{PhD}$ thesis, Université de la Rochelle, La Rochelle, France.

Dodet G, Bertin X and Taborda R (2010) Wave climate variability in the North-East Atlantic Ocean over the last six decades. Ocean Modelling 31(3): 120-131.

Dodet G, Bertin X, Bruneau N, Fortunato AB, Nahon A and Roland A (2013) Wave-current interactions in a wavedominated tidal inlet. Journal of Geophysical Research: Oceans 118(3): 1587-1605.

Elwany MHS, Flick RE and Aijaz S (1998) Opening and closure of a marginal southern California lagoon inlet. Estuaries 21(2): 246-254.

Fortunato $A B$ and Oliveira A (2000) On the representation of bathymetry by unstructured grids. In Computational Methods in Water Resources XIII (Bentley LR (ed.)). Balkema, Rotterdam, the Netherlands, vol. 2, pp. 889-896.

Fortunato $A B$ and Oliveira A (2004) Promoting ebb dominance in coastal lagoons. In Proceedings of the 29th International Coastal Engineering Conference (McKee Smith J (ed.)). World Scientific, Singapore, vol. 2, pp. $1173-1885$.

Fortunato $A B$ and Oliveira $A$ (2007a) Case study: promoting the stability of the Óbidos Lagoon inlet. Journal of Hydraulic Engineering 133(7): 816-824.

Fortunato $A B$ and Oliveira $A$ (2007b) Improving the stability of a morphodynamic modeling system. Journal of Coastal Research, Special Issue 50: 486-490.

Fortunato AB, Nahon A, Dodet G et al. (2014) Morphological evolution of an ephemeral tidal inlet from opening to closure: the Albufeira inlet, Portugal. Continental Shelf Research 73(2): 49-63.

Fortunato AB, Li K, Bertin X et al. (2016) Determination of extreme sea levels along the Iberian Atlantic Coast. Ocean Engineering 111(1): 471-482.

Freitas C, Andrade C and Jones F (1992) Recent evolution of Óbidos and Albufeira coastal lagoons. In Proceedings of the International Coastal Congress ICC-Kiel '92 (Steer H,
Hofstede J and Plag HP (eds)). Peter Lang, New York, NY, USA, pp. 167-186.

Hayes MO (1979) Barrier island morphology as a function of tidal and wave regime. In Barrier Islands from the Gulf of St. Lawrence to the Gulf of Mexico (Leatherman SP (ed.)). Academic Press, New York, NY, USA, pp. 1-27.

Hayes MO and FitzGerald DM (2013) Origin, evolution and classification of tidal inlets. Journal of Coastal Research, Special Issue 69: 14-33.

Hinwood JB and McLean EJ (2015) Predicting the dynamics of intermittently closed/open estuaries using attractors. Coastal Engineering 99(5): 64-72.

Hinwood JB, McLean EJ and Wilson BC (2012) Non-linear dynamics and attractors for the entrance state of a tidal estuary. Coastal Engineering 61(3): 20-26.

IH (Portuguese Hydrographic Institute) (2001) Monitorização Ambiental da Lagoa de Óbidos JUL 2001-DEZ 2001. Relatório de Progresso de Trabalho, Lisbon, Portugal, Report PT. OC. 06/2001 (in Portuguese).

Keshtpoor M, Puleo JA, Shi F and Ma G (2015) 3D numerical simulation of turbulence and sediment transport within a tidal inlet. Coastal Engineering 96(2): 13-26.

Oliveira A, Fortunato AB and Rego JRL (2006) Effect of morphological changes on the hydrodynamics and flushing properties of the Óbidos lagoon (Portugal). Continental Shelf Research 26(8): 917-942.

Pacheco A, Ferreira O and Williams JJ (2011) Long-term morphological impacts of the opening of a new inlet on a multiple inlet system. Earth Surface Processes and Landforms 36(13): 1726-1735.

Ranasinghe R and Pattiaratchi C (2003) The seasonal closure of tidal inlets: causes and effects. Coastal Engineering Journal 45(4): 601-627.

Roelvink D, Reniers A, van Dongeren AP et al. (2009) Modelling storm impacts on beaches, dunes and barrier islands. Coastal Engineering 56(11): 1133-1152.

Roland A, Zhang YJ, Wang HV et al. (2012) A fully coupled 3D wave-current interaction model on unstructured grids. Journal of Geophysical Research: Oceans 117(C11): C00J33.

Shuttleworth B, Woidt A, Paparella T, Herbig S and Walker D (2005) The dynamic behaviour of a river-dominated tidal inlet, River Murray, Australia. Estuarine, Coastal and Shelf Science 64(4): 645-657.

Sutherland J, Peet AH and Soulsby R (2004) Evaluating the performance of morphological models. Coastal Engineering 51(8): 917-939.

Teles MJ, Pires-Silva AA and Belo-Pereira M (2012) Simulations of wave conditions on open beach configuration: wind resolution, seaward forcing and whitecapping effects. European Journal of Environmental and Civil Engineering 16(8): 927-942. 
Tolman HL (2009) User Manual and System Documentation of WAVEWATCH-III Version 3.14. NOAA/NWS/ NCEP/MMAB, Camp Springs, ML, USA,

Technical Note 276.

Van Rijn LC (2007a) Unified view of sediment transport by currents and waves. I: initiation of motion, bed roughness, and bed-load transport. Journal of Hydraulic Engineering 133(6): 649-667.

Van Rijn LC (2007b) Unified view of sediment transport by currents and waves. II: suspended transport. Journal of Hydraulic Engineering 133(6): 668-689.
Vieira JR (2001) Implementation of the environmental management plan of the Óbidos lagoon. In 2as Jornadas Portuguesas de Engenharia Costeira e Portuária (Tavares et al. (eds)). PIANC-Portugal, Lisbon, Portugal (in Portuguese) (CD-ROM).

Zhang Y and Baptista AM (2008) SELFE: a semi-implicit Eulerian-Lagrangian finite-element model for cross-scale ocean circulation. Ocean Modelling 21(3): 71-96.

Zippel S and Thomson J (2015) Wave breaking and turbulence at a tidal inlet. Journal of Geophysical Research: Oceans 120(2): 1016-1103.

\section{WHAT DO YOU THINK?}

To discuss this paper, please email up to 500 words to the editor at journals@ice.org.uk. Your contribution will be forwarded to the author(s) for a reply and, if considered appropriate by the editorial panel, will be published as discussion in a future issue of the journal.

Proceedings journals rely entirely on contributions sent in by civil engineering professionals, academics and students. Papers should be 2000-5000 words long (briefing papers should be 1000-2000 words long), with adequate illustrations and references. You can submit your paper online via www.icevirtuallibrary.com/content/journals, where you will also find detailed author guidelines. 